CIRJE-F-1062

\title{
On the Effect of Bank of Japan's Outright Purchase on the JGB Yield Curve
}

\author{
Masafumi Nakano \\ Graduate School of Ecnonomics, The University of Tokyo \\ Akihiko Takahashi \\ The University of Tokyo \\ Soichiro Takahashi \\ Graduate School of Economics, The University of Tokyo \\ Takami Tokioka \\ GCI Asset Management
}

August 2017; Revised in September, November 2017 and January 2018

CIRJE Discussion Papers can be downloaded without charge from:

http://www.cirje.e.u-tokyo.ac.jp/research/03research02dp.html

Discussion Papers are a series of manuscripts in their draft form. They are not intended for circulation or distribution except as indicated by the author. For that reason Discussion Papers may not be reproduced or distributed without the written consent of the author. 


\title{
On the effect of Bank of Japan's outright purchase on the JGB yield curve
}

\author{
Masafumi Nakano, \\ Graduate School of Ecnonomics, University of Tokyo, 7-3-1 Hongo Bunkyo-ku, Tokyo, Japan, 113-0033 \\ E-mail: msfmnakano325@gmail.com \\ Akihiko Takahashi, \\ Corresponding Author \\ Faculty of Economics, University of Tokyo, 7-3-1 Hongo Bunkyo-ku, Tokyo, Japan, 113-0033 \\ E-mail: akihikot@e.u-tokyo.ac.jp \\ Tel.: +81-3-5841-0682 \\ Soichiro Takahashi \\ Graduate School of Economics, University of Tokyo, 7-3-1 Hongo Bunkyo-ku, Tokyo, Japan, 113-0033 \\ E-mail:s7takahashi1255@gmail.com \\ Takami Tokioka \\ GCI Asset Management, 12F Chiyoda First Bldg. East, 3-8-1 Nishi-Kanda, Chiyoda-ku, Tokyo, Japan, 101-0065 \\ takami.tokioka@gci.jp \\ Forthcoming in Asia-Pacific Financial Markets
}

First version: August 29, 2017, This version: January 4, 2018

\begin{abstract}
This paper examines an impact of Bank of Japan (BOJ)'s outright purchase on the JGB (Japanese government bond) yield curve. Particularly, we develop a simple state space model, which incorporates new factors regarding the BOJ's announcement for its outright purchase and the current market outstanding with standard level and spread factors. Based on the model with a filtering method, we also implement an empirical analysis with time series of the BOJ's announcement records during 2014/10/22-2017/8/3 in the quantitative-qualitative easing(QQE) period to estimate the sensitivities of interest rates against the changes in the market expectation for the net supply with each sector of JGB. We expect the current work provides a basis for considering quantitative effects on the term structure by BOJ's policy changes such as termination or significant reduction of the BOJ's outright purchase. For instance, our scenario analysis shows substantial increase in the 30 year yield with widening of 20-30 year spread.
\end{abstract}

Keywords: yield curve, QQE, Bank of Japan, scenario analysis, state space model, Kalman filter 


\section{Introduction}

It has been widely recognized that an interest rate is one of the most important financial variables which have significant impact on the behaviors of various economic agents such as consumers, producers, corporations and governments. In addition, since interest rates are closely related to the values of financial products, their proper modeling is a central problem in modern finance. As a result, researchers have developed numerous interest rate (term structure, yield curve) models (e.g., Heath, Jarrow, \& Morton, 1992; Ho \& Lee, 1986; Hull \& White, 1990; Vasicek, 1977), which are effectively applied to bond trading, interest rate swap trading, derivatives pricing, and risk management by financial industries such as investment banks and hedge funds.

There are a number of researches for the extension of these traditional interest rate models. For instance, Fujii, Shimada and Takahashi (2010), Fujii and Takahashi (2011) demonstrate the consistent construction of term structures of interest rates in the presence of collateralization. Although these existing term structure models seem to have enough flexibility to express the actual yield curve, they don't explicitly consider the effects of policy or qualitative factors such as political situation, social conditions, international events and government policies, which have in fact serious impacts on the yield curves (e.g., Christiano, Eichenbaum \& Evans, 1999; Gordon \&Leeper, 1994; Strongin, 1995).

To overcome this problem, some researches begin to pay attention to policy or/and qualitative factors in the modeling of interest rates (e.g., Diaz, Theodoulidis \& Dupouy, 2016; Oh \& Han, 2000). For example, Jarrow and Li (2014) extended HJM (Heath, Jarrow, \& Morton, 1992) model to explicitly include the quantitative impact of the Fed's trades on Treasury market prices, in order to consider the effect of the quantitative easing (QE) program on the U.S. term structure of interest rates. Also, Streit and Borenstein (2012) developed a fuzzy agentbased model which incorporates not only the effect of technical indexes, but also the behavior associated with the political, social and economic factors.

In the stream of above new interest rate modeling, we focus on the effect of Bank of Japan's outright purchase on the JGB's (Japanese government bond's) yield curve (term structure of interest rates). Especially, in addition to the market outstanding data, we get access to data to construct a new variable called ENSS in this paper, regarding the market expectation for the net supply of JGB, whose relationship with the change of the JGB yield curve is analyzed in the current work for the first time.

Specifically, Bank of Japan (BOJ) has conducted a large scale of JGB outright purchase in the last several years. In fact, BOJ started the quantitative-qualitative easing (QQE) policy in April 2013, mainly based on its outright purchase of 7 trillion yen per month of JGB. Then, since November 2014, BOJ has adopted the so-called QQE2 policy through increasing its purchase of JGB to 10 trillion yen. Moreover, at the end of each month BOJ publishes a document entitled "Outline of Outright Purchases of Japanese Government Bonds" in the HP to announce a policy of the purchase in the coming month. Also, BOJ has taken the "minus interest rates" policy since February 2016, and adopted the so called yield curve control (YCC) policy to force the 10 year interest rate to the level of 0\% since September 2016.

Because these active non-traditional monetary policies have significant impact on Japanese interest rate markets, it seems meaningful to estimate the concrete effects based on some quantitative analysis. This paper particularly examines the effect of BOJ's announcement for its outright purchase on the JGB yield curve by utilizing the announcement and outright purchase records that can be obtained in the QQE2 period. As for traditional monetary policies before QQE, for instance, see Oda and Ueda (2005) who investigate BOJ's zero interest rate policy from 1999 to 2003. 
Since a market is driven by expectation, at least to a certain extent, a quantitative analysis on the relation between these announcements and yield curves gives us a clue to estimate a concrete impact on the JGB market arising from the future BOJ's policy changes such as termination or substantial reduction of the outright purchase. To the best of our knowledge, this is the first work which incorporates the market expectation into yield curve modeling through BOJ's announcement records. In addition, our analysis considers the current market outstanding of JGB as well as the previous researches (e.g., Fukunaga, Kato \& Koeda, 2015; Hamilton \& Wu 2012).

More specifically, we implement two analyses: Firstly, regression analyses are executed to confirm the basic relation between the change of yield curves and BOJ's announcement for the future purchase. Next, we develop a simple state space model with new variables regarding the BOJ's announcement for its outright purchase and the current market outstanding, in addition to standard level and spread factors. Then, we sequentially estimate the dynamic change in the announcement impact by means of a Bayesian filtering approach. Finally, Section 4.3 implements a scenario analysis based on the estimated result to obtain the quantitative effects of the BOJ's exit strategy on the interest rates.

We remark that state space models are commonly used in the financial literatures ${ }^{1}$ to represent dynamic dependence between latent state and observed variables. Their dynamics are described as time-series models called state and observation equations. Moreover, Bayesian filtering algorithms make it possible to estimate the time transitions of unobservable state variables.

Particularly in the current work, we resort to Kalman filter, introduced and developed by Kalman (1960) and Kalman and Bucy (1961). It has been successfully applied to the estimation of traditional term structure model of interest rates (e.g., Babbs \& Nowman, 1999; Geyer \& Pichler, 1999). Moreover, Takahashi and Sato (2001) have developed a Monte Carlo filtering approach for the estimation of the term structure of interest rates. As an example of the use of JGB data, Tsuda (2003) and Takahashi and Sato (2001) have taken a Kalman or Monte Carlo filtering approach to estimate the dynamic bond pricing model, which enables to express a cross sectional or time series structure of JGB prices.

The remainder of the paper is organized as follows. Section 2 briefly explains the data used in this paper. Section 3 provides results based on a regression analysis. Section 4 implements an analysis with a state space model. Finally, section 5 concludes. Appendix derives a concrete expression of zero yields used in our analysis.

\section{Data}

This section explains the data used in our analysis. First, we briefly show how to construct the zero yields of JGB. Then, we introduce market outstanding data of JGB called "MOS", and new data called "ENSS" regarding market expectation for the net supply of JGB. The time period of these data is 682 days, business days from October 22, 2014 to August 3, 2017, namely from the end of QQE1 to the current QQE2 period. In the subsequent sections, the relation between yield data and these two variables (ENSS and MOS) will be investigated.

\subsection{Interest rate data}

We make the spot zero yields (zero rates) by using the daily par rate data, available on the website of Ministry of Finance (MOF), Japan. While JGB pays its coupon semi-annually, the

\footnotetext{
${ }^{1}$ For instance, see Nakano, Takahashi and Takahashi (2017) [18-20] and Fukui, Sato and Takahashi (2017) [6].
} 
par yields are obtained only for specific maturities, i.e. 1y, 2y, 3y, 4y, 5y, 6y, 7y, 8y, 9y, 10y, 15y, $20 \mathrm{y}, 25 \mathrm{y}, 30 \mathrm{y}, 40 \mathrm{y}$. Therefore, we interpolate the unobserved semi-annual points of par yields by a cubic spline, and then a bootstrap method provides the spot zero yields by using the following equation:

$$
c_{i}=\frac{1-\exp \left(-r_{i} \times i\right)}{0.5 \sum_{j=1}^{2 i} \exp \left(-r_{j / 2} \times j / 2\right)}, i=0.5,1, \cdots, 40,
$$

where $c_{i}$ and $r_{i}$ are par and zero yields with time-to-maturity $i$, respectively. For simplicity, we assume $r_{0.5}=r_{1}$ without avoiding choice of short term interest rates, which seems irrelevant for our subsequent analysis. The resulting continuously compound based 2, 5, 10, 20, 30 year zero yields will be shown in Fig. 1 in Section 2.2.

\section{$2.2 \quad$ Market outstanding}

Let us introduce the following daily variable called " $(M O S)_{t}$ " that stands for the past three month average of the market outstanding at time $t$. Here, the market outstanding in our analysis is defined as "the amount of the central government bonds outstanding" minus "the amount of JGBs held by BOJ", both of which are obtained by the HPs of MOF and BOJ. Also, the maturity sectors used in our analysis consist of 5 ones, namely the 1-3, 3-5, 5-10, 10-25 and over 25 year maturity sectors, into which BOJ has classified JGBs under its purchase program since June 2014.

Fig. 1 presents the total outstanding $(M O S)$ and 2, 5, 10, 20, 30 year zero yields, which indicates that the zero yields tend to decline in accordance with decrease in $M O S$ since the beginning of QQE2. In fact, Table 1 shows the high correlation between MOS and the zero yields.

Table 1: Correlation between MOS and zero yields

\begin{tabular}{ccccc} 
MOS \& 2y & MOS \& 5y & MOS \& 10y & MOS \& 20y & MOS \& 30y \\
\hline 0.78 & 0.72 & 0.76 & 0.77 & 0.74
\end{tabular}

Further, we show the market outstanding for each sector in Fig. 2, where the 10-25 year and over 25 year sectors' outstanding is stable while the other sectors have been decreasing. We remark that the unit of the right (left) in the y-axis of Fig. 1 (Fig. 2) is 1 trillion yen.

Fig. 1: $(M O S)_{t}$ and zero yields

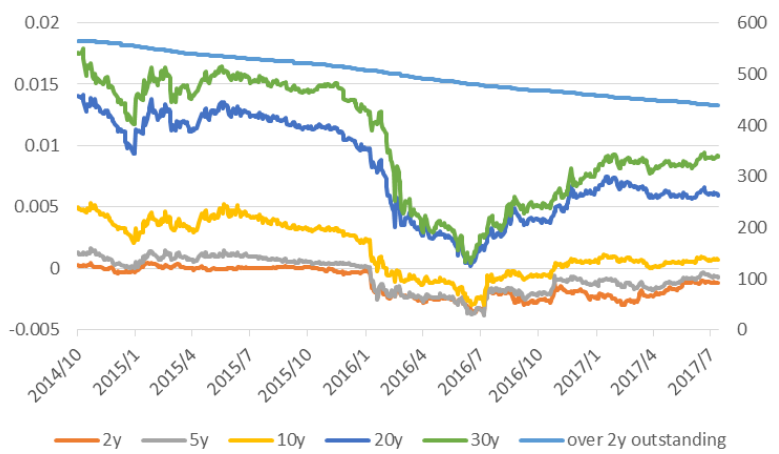

Fig. 2: Market outstanding for each sector

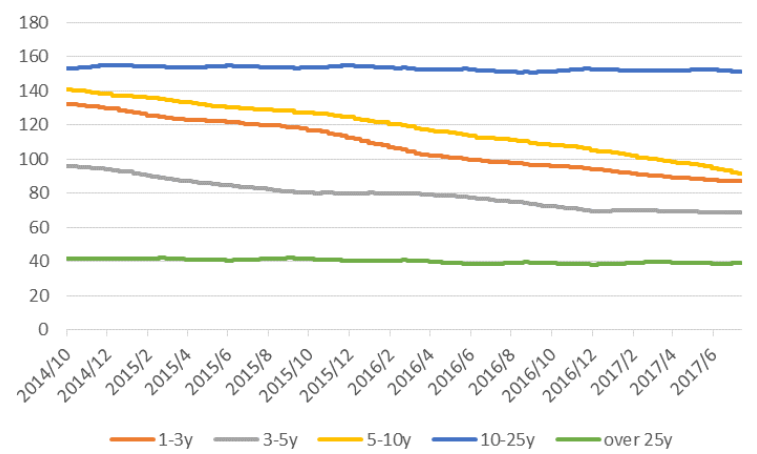




\section{$2.3 \quad$ Expected net supply share (ENSS)}

We also introduce the following daily variable called ENSS (Expected Net Supply Share), and investigate the relation between this ENSS and Japanese yield data in the subsequent sections.

$$
(E N S S)_{t, j}:=\frac{(\text { market expectation for the net annual supply of JGB with } j \text { th sector })_{t}}{(M O S \text { with } j \text { th sector })_{t}}
$$

In the equation above, "(MOS with $j$ th sector $) t$ in the denominator means the past three month average of the market outstanding at time $t$ for the 1-3 $(j=1), 3-5(j=2), 5-10(j=3)$, $10-25(j=4)$ or over $25(j=5)$ year maturity sector. The "market expectation for the net annual supply" appearing in the numerator is defined as "expected supply amount" minus "expected amount of the BOJ's outright purchase" on an annual basis.

Moreover, the "expected supply amount" is defined as the total annual amount of the JGB market issuance (calendar base), non-price competitive auction II (that is assumed to be $5 \%$ of the JGB market issuance) and the auctions for enhanced-liquidity, all of which are reported in the HP of Ministry of Finance. We remark that most of the amount for the next fiscal year's issuance become known at the end of December in the current year. Then, except for the dates in January, February and March, the total issued amount in the fiscal year to which a date belong is applied to the expected supply amount for the date. As for the dates in January, February and March, a linear interpolation between the current and next fiscal year's issued amount is applied, namely 3:1, 2:2, 1:3 for January, February and March, respectively.

Finally, let us define the "expected BOJ's outright purchase amount" as follows: For 2014/10/22$2017 / 3 / 1$, the one at the beginning of a month is defined to be an outright purchase amount announced by BOJ at the end of the previous month. If the outright purchase amount is changed during a month, the market expectation is defined to be the amount after its change.

After 2017/3/1 when the current method is introduced, that is BOJ's announcement is made at a prespecified date, if an announcement for the outright purchase amount at the end of the current month is unchanged from the previous month, the market expectation is defined to be the most recent outright purchase amount. If an announcement is changed from the previous month, the market expectation is defined to be the mid amount in the range of the newly announced outright purchase amount. If the outright purchase amount is changed during a month, the market expectation is defined to be the amount after its change.

It is observed in Fig. 3 that the ENSS for the over 25 (10-25) year's maturity sector shows relatively large (small) fluctuation, mainly due to the small (large) amount of its outstanding. 
Fig. 3: Expected net supply share (ENSS)

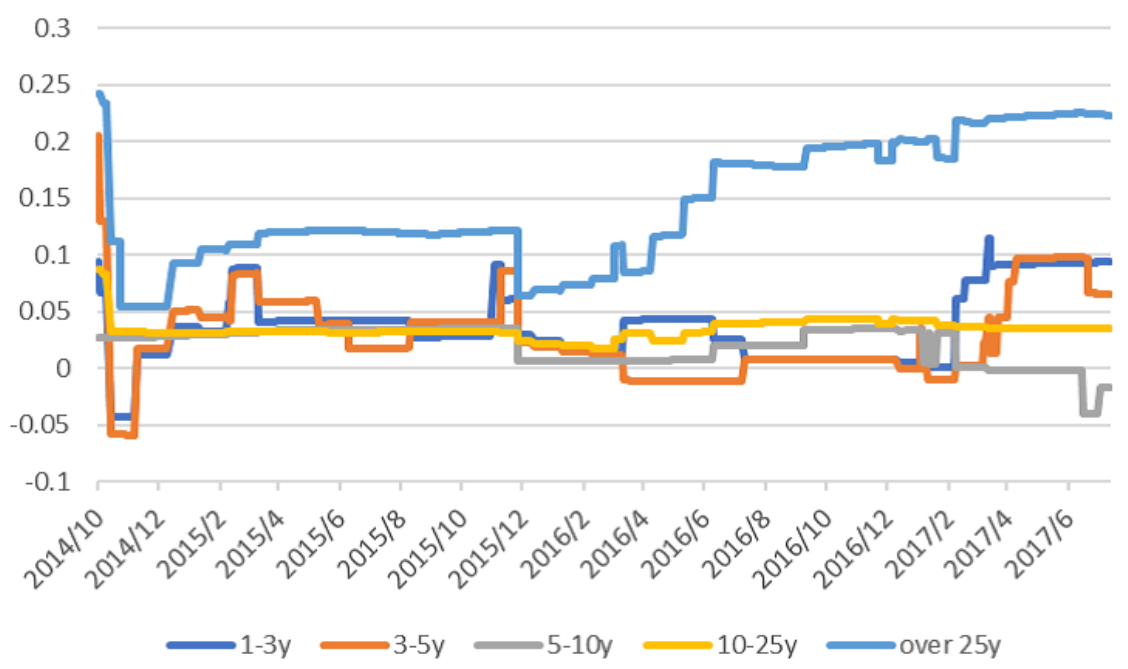

\section{Analysis I: regression}

\subsection{Scatter diagram}

First of all, in order to analyze the yield sensitivity to BOJ's announcement effect, we make a scatter diagram between the change of zero yields and ENSSs on the BOJ's announcement date. Here, we use 2, 5, 10, 20, 30 year yields for the representative yields of the 1-3, 3-5, 5-10, 10-25 and over 25 year sectors, respectively. It is naturally expected that the yield (price) increases (decreases) as the ENSS increases and vice versa, which results in positive correlations among the change of zero yields and ENSSs.

As shown in Fig. 4, the changes of ENSSs and zero yields (percentile) for various sectors seem to be positively correlated, which is also confirmed by Table 2. In particular, ENSS s are largely changed except for the 10y sector on the first business day after the QQE2 introduction, i.e. November 4, 2014, which corresponds with the leftmost points in the 2y, 5y, 20y, 30y graph of Fig. 4. Concretely, the yields have changed by $-0.010 \%,-0.016 \%,-0.087 \%,-0.136 \%$ for $2 \mathrm{y}$, $5 \mathrm{y}, 20 \mathrm{y}$ and $30 \mathrm{y}$ sector, respectively. Moreover, the 10 year sector shows the largest change $-0.030 \%$ on December 18, 2015, namely, the first date after the introduction of QQE2 of BOJ's announcement in the outright purchase for the $10 \mathrm{y}$ sector, as well as the first date of the outright purchase increase in all sectors at the same time. 
Fig. 4: Scatter diagram: changes of ENSS and zero yield

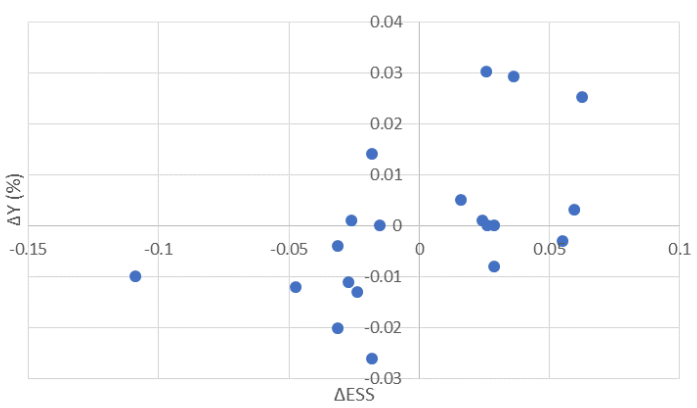

$2 y$

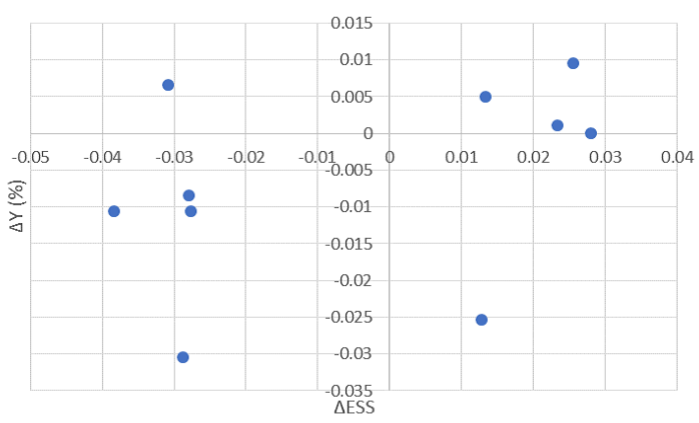

$10 y$

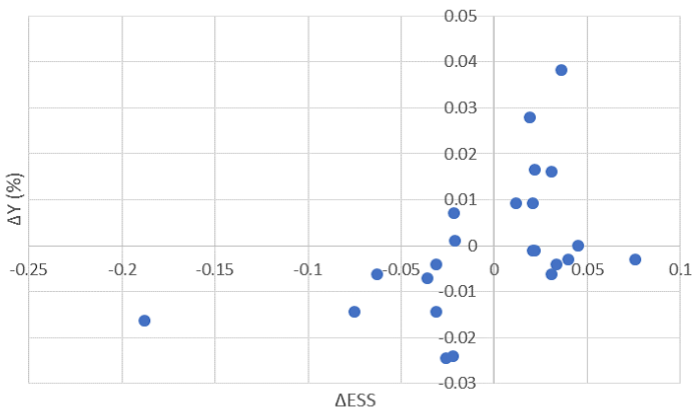

$5 y$

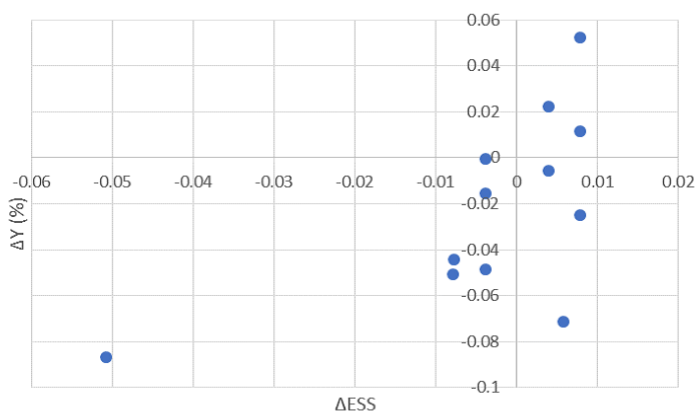

$20 y$

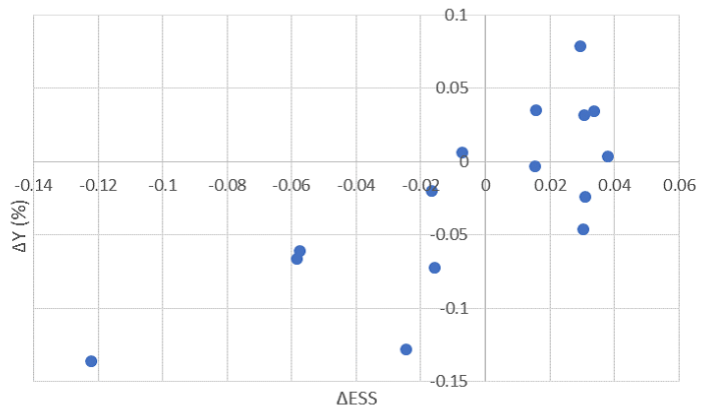

$30 y$

Table 2: Correlation between changes of ENSS and zero yield on the BOJ announcement date

\begin{tabular}{ccccc}
$2 \mathrm{y}$ & $5 \mathrm{y}$ & $10 \mathrm{y}$ & $20 \mathrm{y}$ & $30 \mathrm{y}$ \\
\hline 0.53 & 0.48 & 0.39 & 0.62 & 0.76
\end{tabular}

\subsection{Multiple regression}

Although the positive correlation between the ENSS and the zero yield clearly appears in Fig. 4, there are also some outliers, which are often affected by the announcements of different 
sectors on the same day. Therefore, we additionally run a multiple regression analysis without an intercept, where a dependent variable is a change of zero yield, and independent variables are changes of ENSSs for all sectors. Table 3 provides the results of the multiple regression analysis.

Table 3: Result of regression

\begin{tabular}{|c|c|c|c|c|c|c|}
\hline & Estimate & Std & $t$-value & $\operatorname{Pr}(>|t|)$ & & \\
\hline \multicolumn{7}{|c|}{$2 y$ zero yield } \\
\hline $1-3 y$ & 0.0021 & 0.0011 & 1.9170 & 0.0745 & $R^{2}$ & 0.3902 \\
\hline $3-5 y$ & 0.0009 & 0.0010 & 0.9009 & 0.3819 & adjusted $R^{2}$ & 0.1869 \\
\hline $5-10 y$ & 0.0007 & 0.0027 & 0.2623 & 0.7967 & & \\
\hline $10-25 y$ & -0.0062 & 0.0053 & -1.1801 & 0.2563 & & \\
\hline over $25 y$ & -0.0001 & 0.0019 & -0.0272 & 0.9787 & & \\
\hline \multicolumn{7}{|c|}{$5 y$ zero yield } \\
\hline $1-3 y$ & 0.0005 & 0.0013 & 0.3527 & 0.7284 & $R^{2}$ & 0.2959 \\
\hline $3-5 y$ & 0.0018 & 0.0010 & 1.7546 & 0.0963 & adjusted $R^{2}$ & 0.1003 \\
\hline $5-10 y$ & -0.0009 & 0.0029 & -0.3188 & 0.7536 & & \\
\hline $10-25 y$ & -0.0063 & 0.0055 & -1.1389 & 0.2697 & & \\
\hline over $25 y$ & 0.0006 & 0.0020 & 0.2892 & 0.7758 & & \\
\hline \multicolumn{7}{|c|}{ 10y zero yield } \\
\hline $1-3 y$ & -0.0036 & 0.0048 & -0.7598 & 0.4816 & $R^{2}$ & 0.7831 \\
\hline $3-5 y$ & 0.0055 & 0.0030 & 1.8450 & 0.1243 & adjusted $R^{2}$ & 0.5661 \\
\hline $5-10 y$ & 0.0014 & 0.0014 & 0.9662 & 0.3783 & & \\
\hline $10-25 y$ & -0.0639 & 0.0427 & -1.4967 & 0.1947 & & \\
\hline over $25 y$ & 0.0086 & 0.0073 & 1.1694 & 0.2949 & & \\
\hline \multicolumn{7}{|c|}{ 20y zero yield } \\
\hline $1-3 y$ & -0.0129 & 0.0102 & -1.2721 & 0.2440 & $R^{2}$ & 0.5808 \\
\hline $3-5 y$ & 0.0097 & 0.0073 & 1.3158 & 0.2297 & adjusted $R^{2}$ & 0.2813 \\
\hline $5-10 y$ & -0.0032 & 0.0097 & -0.3331 & 0.7488 & & \\
\hline $10-25 y$ & 0.0116 & 0.0206 & 0.5634 & 0.5907 & & \\
\hline over $25 y$ & -0.0002 & 0.0064 & -0.0297 & 0.9771 & & \\
\hline \multicolumn{7}{|c|}{$30 \mathrm{y}$ zero yield } \\
\hline $1-3 y$ & -0.0115 & 0.0081 & -1.4248 & 0.1847 & $R^{2}$ & 0.6368 \\
\hline $3-5 y$ & 0.0090 & 0.0075 & 1.1872 & 0.2626 & adjusted $R^{2}$ & 0.4552 \\
\hline $5-10 y$ & -0.0116 & 0.0109 & -1.0567 & 0.3155 & & \\
\hline $10-25 y$ & -0.0008 & 0.0194 & -0.0392 & 0.9695 & & \\
\hline over $25 y$ & 0.0089 & 0.0049 & 1.7984 & 0.1023 & & \\
\hline
\end{tabular}

While Table 2 shows the relatively low correlation for the 10 year yield, we can see the adjusted $R^{2}$ in the multiple regression is improved. In addition, it is clear that the adjusted $R^{2} \mathrm{~s}$ on the 2 year and 5 year yields are low, which implies that there are other factors affecting the yield changes.

\subsection{Regression analysis considering model effect}

In order to take a closer look at the BOJ's announcement effect, we introduce a simple yield curve model representing the so called level factor, which is well-known to explain the largest 
part of the variation in the term structure of interest rates. (e.g., For the details, see Heidari and $\mathrm{Wu}(2003)$ based on principal component analysis, and Takahashi and Sato (2001) based on a Monte Carlo filtering method.)

First, we briefly explain a setting for a standard term structure model. (e.g., See chapter 6.5 and chapter 10 in Shreve (2004) for the detail.) Let us denote the short rate (i.e. unobservable instantaneous spot rate) at time $t$ and the zero coupon bond's price at time $t$ with the maturity $T$ by $r_{t}$ and $P(t, T)$, respectively. Next, we suppose the filtered probability space $\left(\Omega, \mathcal{F},\left\{\mathcal{F}_{t}\right\}, \mathbb{Q}\right)$ is given, where $\mathbb{Q}$ is the so called "risk-neutral probability measure" or "equivalent martingale measure". Then, recalling that a zero coupon bond gives no coupons and pays 1 to a bond holder at maturity, we have

$$
P(t, T)=\mathbb{E}^{\mathbb{Q}}\left[e^{-\int_{t}^{T} r_{u} d u} P(T, T) \mid \mathcal{F}_{t}\right]=\mathbb{E}^{\mathbb{Q}}\left[e^{-\int_{t}^{T} r_{u} d u} \mid \mathcal{F}_{t}\right] .
$$

In particular, we adopt a Gaussian short rate model with no mean-reversion, which stands for the level factor in the term structure of interest rates, as will be confirmed in Section 4.2. That is, a (risk-neutral) short rate process $r_{t}$ is described as follows:

$$
r_{t}=r_{0}+\lambda t+\sigma W_{t}^{\mathbb{Q}}
$$

where $r_{0}, \lambda$ and $\sigma$ are constant, and $W^{\mathbb{Q}}$ is a one dimensional Brownian motion under a riskneutral measure $\mathbb{Q}$. In this model, a straightforward calculation shows that a zero-coupon bond price $P(t, T)$ is given as follows:

$$
P(t, T)=\exp \left\{-r_{t}(T-t)-\lambda \frac{(T-t)^{2}}{2}+\sigma^{2} \frac{(T-t)^{3}}{6}\right\} .
$$

As a result, the time- $t$ zero yield with time-to-maturity $\tau=T-t$ defined as $Y_{t}^{m}(\tau ; \lambda, \sigma)=$ $-\log (P(t, T)) /(T-t)$ is obtained by

$$
Y_{t}^{m}(\tau ; \lambda, \sigma)=r_{t}+\frac{\lambda}{2} \tau-\frac{\sigma^{2}}{6} \tau^{2}
$$

Then, to examine the BOJ's announcement effect on the changes in the interest rates after excluding those explained by a short rate model, we use a regression analysis. Specifically, if $Y_{t}^{o}(\tau)$ denotes the observed zero yield with a time-to-maturity $\tau$ at date $t$, the dependent variable is set to be the change in the difference between $Y_{t}^{o}(\tau)$ and $Y_{t}^{m}(\tau ; \lambda, \sigma)$ :

$$
\left\{Y_{t}^{o}(\tau)-Y_{t}^{m}(\tau ; \lambda, \sigma)\right\}-\left\{Y_{t-1}^{o}(\tau)-Y_{t-1}^{m}(\tau ; \lambda, \sigma)\right\} .
$$

The independent variables are changes of ENSS for all sectors as in the previous subsection. Let us remark the estimation procedure for $r$ and the parameters in the model's zero yield $Y_{t}^{m}(\tau ; \lambda, \sigma)$. Suppose that BOJ announces its change for the future purchase schedule at date $t$. First, we calibrate $r_{t-1}, \lambda, \sigma$ at $t-1$, namely the date just before the announcement, which gives us $Y_{t-1}^{m}(\tau ; \lambda, \sigma)$. Then, using the calibrated parameter $\lambda$ and $\sigma$ at date $t-1$, we recalibrate only $r_{t}$ at date $t$, which enables us to obtain $Y_{t}^{m}(\tau ; \lambda, \sigma)$. 
Table 4: Result of regression considering model effect

\begin{tabular}{|c|c|c|c|c|c|c|}
\hline & Estimate & Std & $t$-value & $\operatorname{Pr}(>|t|)$ & & \\
\hline \multicolumn{7}{|c|}{$2 y$ zero yield } \\
\hline $1-3 y$ & 0.0022 & 0.0010 & 2.2853 & 0.0373 & $R^{2}$ & 0.5329 \\
\hline $3-5 y$ & -0.0010 & 0.0010 & -1.0989 & 0.2891 & adjusted $R^{2}$ & 0.3772 \\
\hline $5-10 y$ & 0.0023 & 0.0025 & 0.9234 & 0.3704 & & \\
\hline $10-25 y$ & 0.0004 & 0.0048 & 0.0830 & 0.9350 & & \\
\hline over $25 y$ & -0.0033 & 0.0017 & -1.9431 & 0.0710 & & \\
\hline \multicolumn{7}{|c|}{ 5y zero yield } \\
\hline $1-3 y$ & 0.0014 & 0.0006 & 2.3536 & 0.0302 & $R^{2}$ & 0.7640 \\
\hline $3-5 y$ & 0.0007 & 0.0005 & 1.4158 & 0.1739 & adjusted $R^{2}$ & 0.6985 \\
\hline $5-10 y$ & -0.0013 & 0.0013 & -0.9795 & 0.3403 & & \\
\hline $10-25 y$ & -0.0010 & 0.0025 & -0.4008 & 0.6933 & & \\
\hline over $25 \mathrm{y}$ & -0.0045 & 0.0009 & -4.9116 & 0.0001 & & \\
\hline \multicolumn{7}{|c|}{$10 y$ zero yield } \\
\hline $1-3 y$ & 0.0021 & 0.0017 & 1.2134 & 0.2792 & $R^{2}$ & 0.8376 \\
\hline $3-5 y$ & -0.0019 & 0.0011 & -1.7686 & 0.1372 & adjusted $R^{2}$ & 0.6753 \\
\hline $5-10 y$ & 0.0021 & 0.0005 & 4.1270 & 0.0091 & & \\
\hline $10-25 y$ & 0.0231 & 0.0152 & 1.5143 & 0.1904 & & \\
\hline over $25 y$ & -0.0029 & 0.0026 & -1.1062 & 0.3190 & & \\
\hline \multicolumn{7}{|c|}{ 20y zero yield } \\
\hline $1-3 y$ & -0.0065 & 0.0038 & -1.7175 & 0.1296 & $R^{2}$ & 0.6804 \\
\hline $3-5 y$ & 0.0030 & 0.0027 & 1.1106 & 0.3034 & adjusted $R^{2}$ & 0.4521 \\
\hline $5-10 y$ & -0.0019 & 0.0036 & -0.5141 & 0.6230 & & \\
\hline $10-25 y$ & 0.0092 & 0.0077 & 1.1910 & 0.2725 & & \\
\hline over $25 y$ & 0.0007 & 0.0024 & 0.2913 & 0.7792 & & \\
\hline \multicolumn{7}{|c|}{ 30y zero yield } \\
\hline $1-3 y$ & -0.0088 & 0.0043 & -2.0565 & 0.0668 & $R^{2}$ & 0.7446 \\
\hline $3-5 y$ & 0.0053 & 0.0040 & 1.3324 & 0.2123 & adjusted $R^{2}$ & 0.6169 \\
\hline $5-10 y$ & -0.0083 & 0.0058 & -1.4317 & 0.1827 & & \\
\hline $10-25 y$ & 0.0008 & 0.0102 & 0.0829 & 0.9355 & & \\
\hline over $25 y$ & 0.0069 & 0.0026 & 2.6639 & 0.0237 & & \\
\hline
\end{tabular}

Table 4 shows the result for the multiple regression analysis after excluding the short rate model's effect. Comparing with Table 3, we can see that the adjusted $R^{2}$ is improved in all sectors. We also note that the estimated coefficients of its own sector is positive and its $t$-value is relatively high in all sectors.

\section{Analysis II: state space approach}

Since ENSS changes in the 10-25 sector always occurs at the same time as those in the 25$40 \mathrm{y}$ sector, we introduce a new ENSS that integrates those of the 10-25y and 25-40y sectors. Specifically, the new ENSS for the "over 10y" sector, the integrated sector is defined as follows. 
$(E N S S)_{t, \text { over10y }}:=\frac{\sum_{j=4}^{5}(\text { market expectation for the net annual supply of JGB with } j \text { th sector })_{t}}{\sum_{j=4}^{5}(M O S \text { with } j \text { th sector })_{t}}$

Hereafter, index $j=4$ refers to the "over 10y" sector, and this new ENSS is shown below with other sectors' ones.

Fig. 5: Expected net supply share (ENSS)

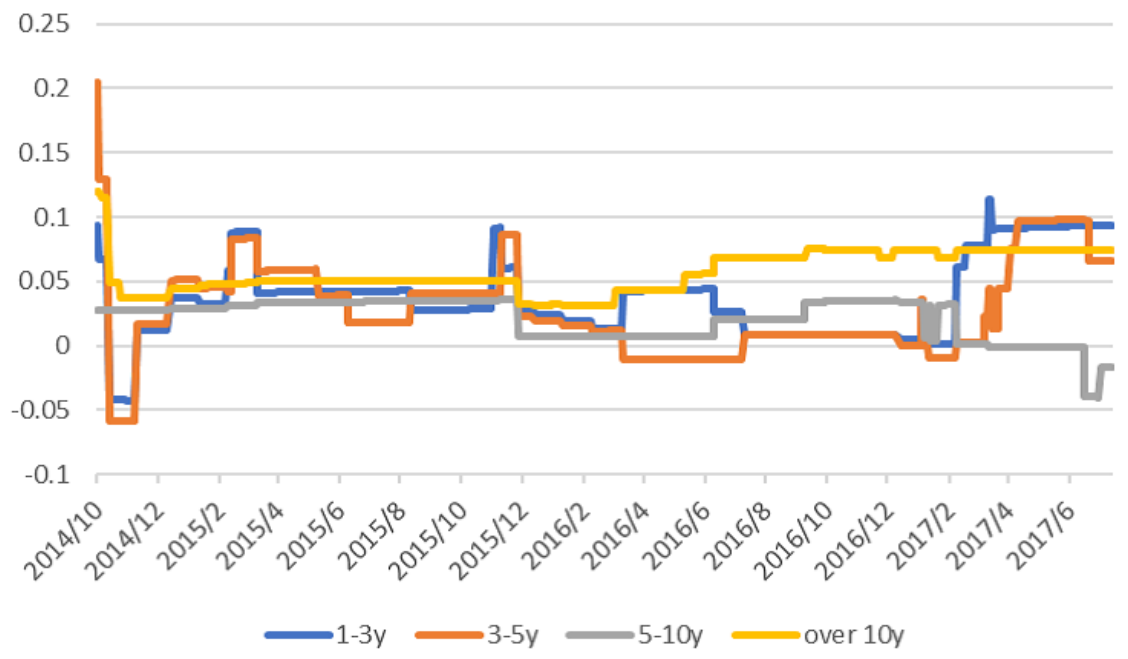

\subsection{State space model}

In this subsection, in order to refine the results obtained in the previous section, we introduce a new state space model, which provides an extension of the above analysis mainly in the following two points.

First, the traditional short rate model is extended to have two factors. As stated above, although the one factor model used in Section 3.3 is able to represent the change in the level of the yield curve, it cannot handle with the steepening and flattening of the yield curve. Thus, we introduce another factor which corresponds to the short-long term spread factor. The details are explained in Section 4.1.1.

Second, as the main contribution of this paper, we extend the yield curve model to explicitly include not only $M O S$ but also ENSS factor, which corresponds to the market expectation. We will describe the whole model in Section 4.1.2.

\subsubsection{Extension of the traditional short rate model}

In this section, we assume that the short rate $r_{t}$ is the sum of two variables $x_{t, 1}$ and $x_{t, 2}$ :

$$
r_{t}=x_{t, 1}+x_{t, 2} \text {. }
$$

In order to make $x_{t, 1}$ and $x_{t, 2}$ a yield curve level factor and a short-long spread factor, we assume that $x_{t, 1}$ and $x_{t, 2}$ follow the next stochastic processes:

$$
\begin{aligned}
& d x_{t, 1}=\lambda d t+\sigma_{1} d W_{t, 1}^{\mathbb{Q}}, \\
& d x_{t, 2}=-\kappa x_{t, 2} d t+\sigma_{2} d W_{t, 2}^{\mathbb{Q}},
\end{aligned}
$$


where $W_{t, 1}^{\mathbb{Q}}$ and $W_{t, 2}^{\mathbb{Q}}$ are one dimensional Brownian motions with correlation $\rho$ under risk-neutral measure $\mathbb{Q}$. Since $x_{t, 2}$ follows a mean reversion process with zero mean reversion level, and hence $r_{t}$ moves from $x_{t, 1}+x_{t, 2}$ to $x_{t, 1}$ for large enough $\kappa$, the factor $x_{t, 2}$ affects mainly the short term part. Therefore, we can expect $x_{t, 2}$ to play a role of short-long term spread factor.

Under this two factor short rate model, a similar calculation as in Section 3.3 shows that the time- $t$ zero yield with time-to-maturity $\tau, Y_{t}(\tau)$ is obtained as follows ${ }^{2}$ :

$$
Y_{t}(\tau)=-\frac{1}{\tau} \log P(t, t+\tau)=X_{t, 1}(\tau)+X_{t, 2}(\tau)+C(\tau)
$$

where

$$
\begin{aligned}
& X_{t, 1}(\tau)=x_{t, 1}+\frac{\lambda}{2} \tau-\frac{\sigma_{1}^{2}}{6} \tau^{2}, \\
& X_{t, 2}(\tau)=\frac{1}{\tau}\left\{B(\tau) x_{t, 2}+A(\tau)\right\}, \\
& B(\tau):=\frac{1-e^{-\kappa \tau}}{\kappa}, \quad A(\tau):=-\frac{1}{2}\left(\frac{\sigma_{2}}{\kappa}\right)^{2}\left[\tau-2 B(\tau)+\frac{1-e^{-2 \kappa \tau}}{2 \kappa}\right], \\
& C(\tau)=-\frac{\rho \sigma_{1} \sigma_{2}}{\kappa \tau}\left\{\frac{\tau^{2}}{2}+\frac{\tau e^{-\kappa \tau}-B(\tau)}{\kappa}\right\} .
\end{aligned}
$$

\subsubsection{Model with MOS and ENSS}

Based on the model (12), we employ the following linear-Gaussian state space model to feature the dynamics of JGB yield curve, where $M O S_{t}$ and $\left(E N S S_{t, j}\right)_{j}$ are incorporated into the traditional two factor short rate model.

[observation equation] :

$Y_{t}\left(\tau_{i}\right)=X_{t, 1}\left(\tau_{i}\right)+X_{t, 2}\left(\tau_{i}\right)+C\left(\tau_{i}\right)+a_{t, i} M O S_{t}+\sum_{j=1}^{4} b_{t, i, j} E N S S_{t, j}+\sigma_{o, i} \epsilon_{t, i} ; \quad i=1, \cdots, 5$,

[system equation] :

$$
\begin{aligned}
& x_{t, 1}=x_{t-\Delta t, 1}+\sigma_{1} \sqrt{\Delta t} \eta_{t} \\
& x_{t, 2}=e^{-\kappa \Delta t} x_{t-\Delta t, 2}+\sigma_{2} \sqrt{\frac{1-e^{-2 \kappa \Delta t}}{2 \kappa}} \nu_{t}, \quad\left(\begin{array}{l}
\eta_{t} \\
\nu_{t}
\end{array}\right) \sim i . i . d . N\left(\left(\begin{array}{l}
0 \\
0
\end{array}\right),\left(\begin{array}{ll}
1 & \rho \\
\rho & 1
\end{array}\right)\right) \\
& a_{t, i}=a_{t-\Delta t, i}+\sigma_{a, i} \xi_{t, i}, \quad b_{t, i, j}=b_{t-\Delta t, i, j}+\sigma_{b, i, j} \zeta_{t, i, j}, \quad i=1, \cdots, 5, j=1, \cdots, 4
\end{aligned}
$$

where $\left\{\sigma_{o, i}\right\}_{i}, \lambda, \sigma_{1}, \kappa, \theta, \sigma_{2}, \rho,\left\{\sigma_{a, i}\right\}_{i},\left\{\sigma_{b, i, j}\right\}_{i, j}$ are constant parameters, and $\left\{\epsilon_{t, i}\right\}_{i},\left\{\xi_{t, i}\right\}_{i},\left\{\zeta_{t, i, j}\right\}_{i, j}$ independently and identically follow standard normal distributions $N(0,1)$.

Also, in the observation equation, $\left\{\sigma_{o, i} \epsilon_{t, i}\right\}_{i}$ stand for observation noises. With regard to each standard deviation of the observation noise $\left\{\sigma_{o, i}\right\}_{i}$, we use 0.01 times the sample standard deviation of each zero yield.

In the system equation, $x_{t, 1}$ and $x_{t, 2}$ are assumed to be discretized processes of $d x_{t, 1}=$ $\sigma_{1} d W_{t, 1}$ and $d x_{t, 2}=-\kappa x_{t, 2} d t+\sigma_{1} d W_{t, 2}$, respectively with correlated Brownian motions $W_{t, i}(i=$ $1,2)$ and an appropriate market price of risk under the physical probability measure.

We also set $\Delta t$, the length of the time step as $\Delta t=1 / 250$.

\footnotetext{
${ }^{2}$ See Appendix for details.
} 
Moreover, while MOS and ENSS are observable variables, we introduce additional state variables $\left(a_{t, i}\right)_{i}$ and $\left(b_{t, i, j}\right)_{i, j}$ following random walks, which correspond to the coefficients of $M O S$ and $E N S S$, respectively. Namely, $a_{t, i}$ and $\left(b_{t, i, j}\right)_{i, j}$ show the time- $t$ sensitivities of the spot yield with term $\tau_{i}$ against $M O S_{t}$ and the maturity sector $j$ of $E N S S$ (i.e. $E N S S_{t, j}$ ), respectively. Here, $\tau_{i}, i=1,2,3,4,5$ stand for the $2,5,10,20,30$ years, and $j=1,2,3,4$ represent the 1-3, 3-5, 5-10, over 10 year maturity sectors, respectively. By regarding those as time-varying state variables, we are able to estimate their changes through time, which helps us to understand the BOJ's purchase effects more precisely than in the previous regression analyses.

To set the system noises $\left\{\sigma_{a, i}\right\}_{i}$ and $\left\{\sigma_{b, i, j}\right\}_{i, j}$, we utilize the multiple regression analysis. First, since a new ENSS sector "over 10y" is introduced instead of "10-25y" and "over 25y", we re-implement a multiple regression in the same way as in Section 3.3. Then, we use 0.05 times the values of the standard deviations obtained in the multiple regression as $\left\{\sigma_{b, i, j}\right\}_{i, j}$, where the multiplier 0.05 was the best specification in our numerical analysis for identification of level, spread, MOS and ENSS factors. Next, using these results, we further run simple regressions with intercepts, where for each $i$, the dependent variable is $Y_{t}\left(\tau_{i}\right)-\sum_{j=1}^{4} \tilde{b}_{i, j} E N S S_{t, j}$ and an independent variable is MOS. Here, $\left(\tilde{b}_{i, j}\right)_{i, j}$ are the estimated coefficients calculated by the above multiple regression. Then, for each $\left\{\sigma_{a, i}\right\}_{i}$, we set 0.05 times the values of the standard deviations obtained by these simple regressions.

As for estimation of state variables, we apply Kalman filter to this linear-Gaussian state space model. Here, we obtain the estimates of constant parameters $\lambda, \sigma_{1}, \kappa, \sigma_{2}, \rho$ by a maximum likelihood method, where the likelihood can also be calculated by Kalman filter.

We also note that the above formulation implicitly involves a sort of endogeneity problem. For instance, in Eq. (13) $E N S S_{t, j}$ is likely to be correlated with the zero yield levels, because BOJ decides JGBs' purchasing amount referring to the interest rate levels, in addition to other macroeconomic variables such as inflation rates and GDP. ${ }^{3}$

More concretely, at the introduction of the YCC policy, BOJ stated that it would purchase JGBs so that the 10 year JGB yield rate would remain more or less at $0 \%$. In fact, when the market interest rates deviated from the related target levels to certain extents, BOJ also implemented the fixed rate method once for the 1-3 and 3-5 year sectors as well as twice for the 5-10 year sector: On November 17, 2016, BOJ showed the purchase price at $-0.09 \%$ for the 2 year current issue and at $-0.04 \%$ for the 5 year current issue. On February 3, 2017 and July 7,2017 , it showed the purchase price at $0.11 \%$ for the 10 year current issue. Hence, one of the further extensions is to take the endogeneity into consideration by adding observation equations for $E N S S_{t, j}$.

\subsection{Result of estimation}

In the subsequent figures of sequential estimations, we omit the first 15 periods to show as many results as possible, though the 15 periods might not be enough to exclude the effects from initial values of the state variables. Nevertheless, in the parameter estimation and correlation calculation (i.e. Table 5, 6 and 7), we omit the first 100 results to completely exclude the initial values' effects.

\footnotetext{
${ }^{3}$ We appreciate Professor Kazuo Ueda for pointing out this observation.
} 
Fig. 6: Result of Kalman filter

$\mathrm{x} 1$

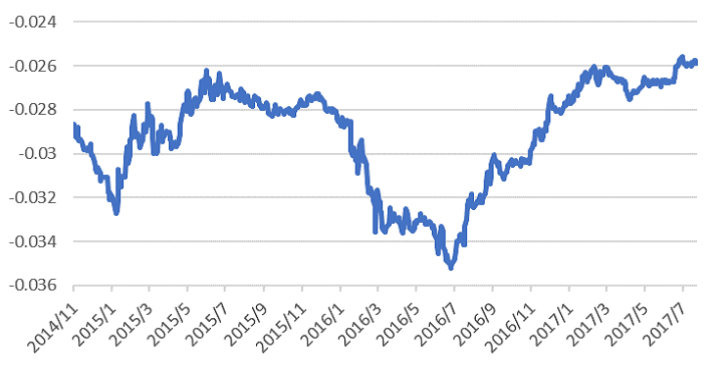

1st factor $x_{t, 1}$ $x 2$

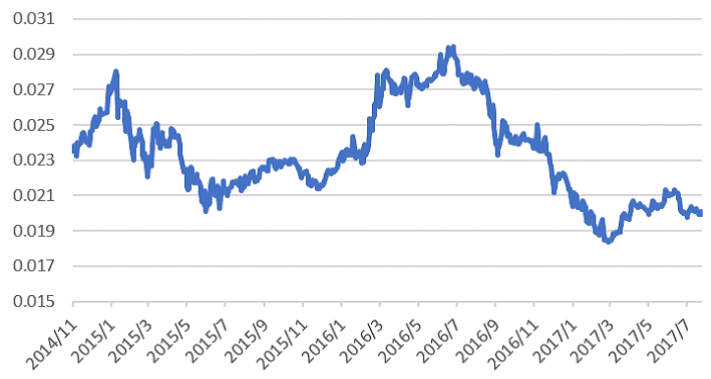

2nd factor $x_{t, 2}$

Table 5: Estimation results of constant parameters

\begin{tabular}{ccccc}
$\lambda$ & $\sigma_{1}$ & $\kappa$ & $\sigma_{2}$ & $\rho$ \\
\hline $0.0025 \%$ & $0.36 \%$ & 0.30 & $0.47 \%$ & -0.84
\end{tabular}

Fig. 6 presents the sequential estimations of standard two factor state variables $x_{1}$ and $x_{2}$, and Table 5 shows the reasonable estimates for the parameters in the processes $x_{1}$ and $x_{2}$. In Table 6 and 7 , it is clear that $x_{1}$ and $x_{2}$ are highly correlated to zero yield and short-long spread, respectively, which implies that those state variables stand for level and spread factors, as expected.

Table 6: Correlation between $x_{1}$ and zero rate

\begin{tabular}{c|ccccc} 
& $2 \mathrm{y}$ & $5 \mathrm{y}$ & $10 \mathrm{y}$ & $20 \mathrm{y}$ & $30 \mathrm{y}$ \\
\hline$x_{1}$ & 0.516 & 0.675 & 0.655 & 0.647 & 0.666
\end{tabular}

Table 7: Correlation between $x_{2}$ and short-long spread

\begin{tabular}{c|cccc} 
& $2 \mathrm{y}-5 \mathrm{y}$ & $2 \mathrm{y}-10 \mathrm{y}$ & $2 \mathrm{y}-20 \mathrm{y}$ & $2 \mathrm{y}-30 \mathrm{y}$ \\
\hline$x_{2}$ & 0.775 & 0.662 & 0.601 & 0.617
\end{tabular}

Fig. 7 displays estimation results of the state variables corresponding to the coefficients of BOJ's policy factors. Remark that $y$ axis in the figure represents the sensitivity of a zero yield against the change in $E N S S_{j}$ or MOS. For example, the recent coefficient estimates suggest that if ENSS of the over 10 year sector changes by $1 \%$, the changes of $20 \mathrm{y}$ yield and $30 \mathrm{y}$ yield are about 1.0 bps ( $b_{t, 4,4}$ in Fig. 7-d.) and 2.8 bps ( $b_{t, 5,4}$ in Fig. 7-e.), respectively, while the 2y, $5 y, 10 y$ yields change by about $0.3,0.1,0.2$ bps $\left(b_{t, 1,1}, b_{t, 2,2}, b_{t, 3,3}\right.$ in Fig. 7-a.,b., c.) if ENSSs of the 1-3y, 3-5y, 5-10y sectors change by $1 \%$, respectively. Moreover, for the long maturity sectors such as $20 \mathrm{y}$ and $30 \mathrm{y}$, we can see that the coefficients increase with time in general, namely, the sensitivities of the market interest rates against the changes in the expected net supply become large with time.

The recent difference of the sensitivity (coefficient) levels between the short and long maturities $(2 \mathrm{y}, 5 \mathrm{y}, 10 \mathrm{y}$ vs $20 \mathrm{y}, 30 \mathrm{y})$ seems mainly due to the minus interest rates policy at short end 
(-0.1\% on each financial institution's current accounts at BOJ) and the $0 \%$ target of the 10 year rate with the fixed rate method actually implemented once for the 1-3 and 3-5 year sectors as well as twice for the 5-10 year sector in the YCC framework. On the other hand, there are no explicit restrictions for the long term rates $(20 \mathrm{y}, 30 \mathrm{y})$, and the recent increase of the coefficients may reflect an unstable sentiment and a decline of liquidity in the JGB market.

Also, let us note that the recent sensitivities of the 2, 5, 10, 20, 30 year yields are around 0.2, $0.3,0.5,0.6,0.7 \mathrm{bps}$, respectively against 1 trillion yen changes of the total market outstanding, and the 20 and 30 year yields' sensitivities have declined after the introduction of the minus interest rates policy in February, 2016.

From Fig. 7, we can also see that the estimated coefficients of its own sector are positive through the period, which is consistent to the result of the multiple regression analysis in the previous section. 
Fig. 7: Result of estimation for ENSS \& MOS coefficient
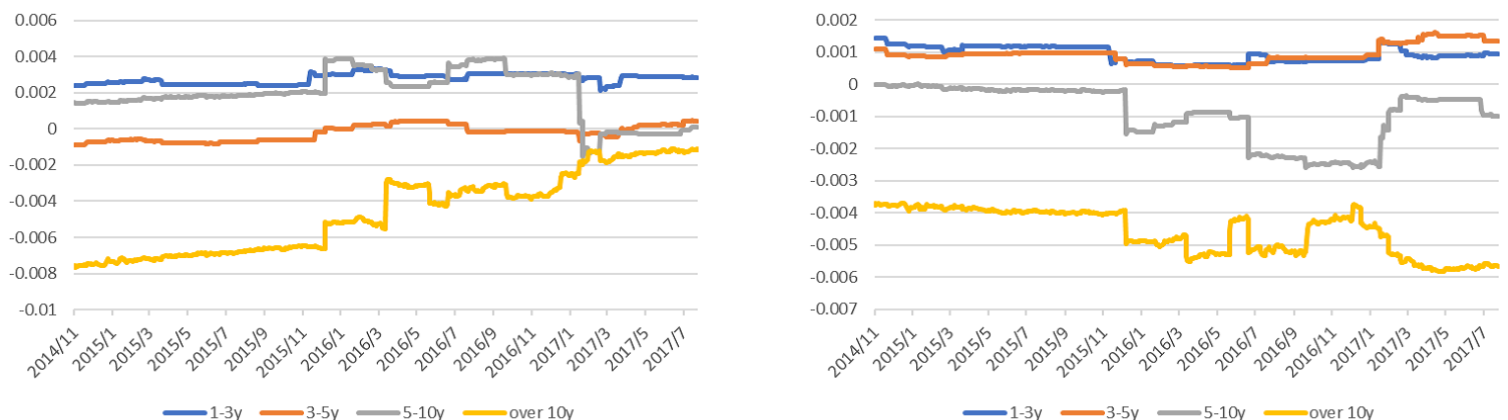

a.sensitivity of $2 \mathrm{y}$ yield against $E N S S,\left(b_{t, 1, j}\right)_{j}$ b.sensitivity of $5 \mathrm{y}$ yield against $\operatorname{ENSS},\left(b_{t, 2, j}\right)_{j}$
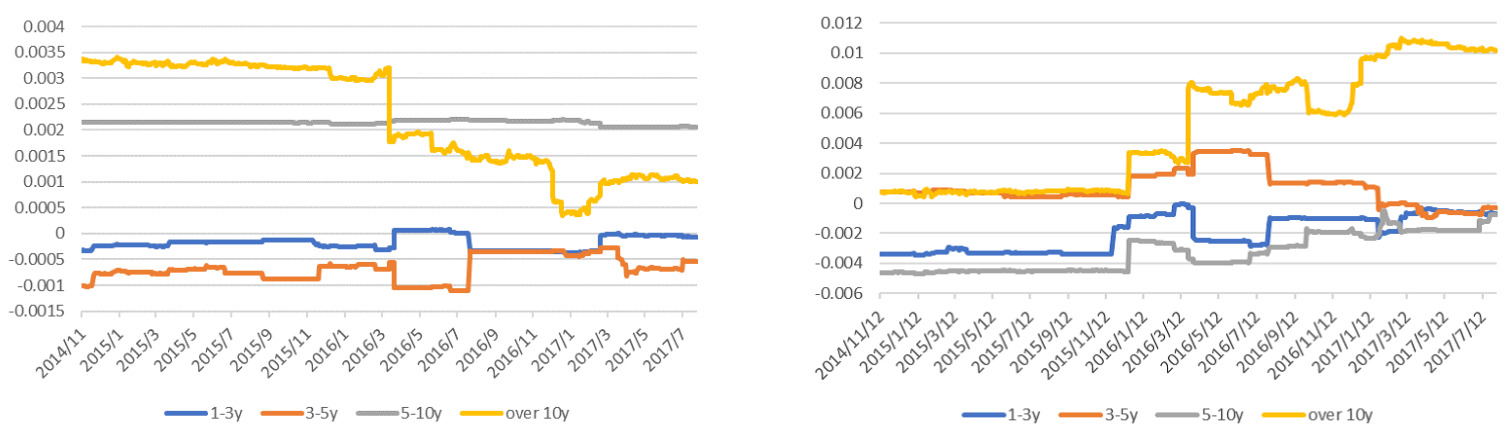

c.sensitivity of $10 \mathrm{y}$ yield against $E N S S,\left(b_{t, 3, j}\right)_{j}$ d.sensitivity of $20 \mathrm{y}$ yield against $E N S S,\left(b_{t, 4, j}\right)_{j}$
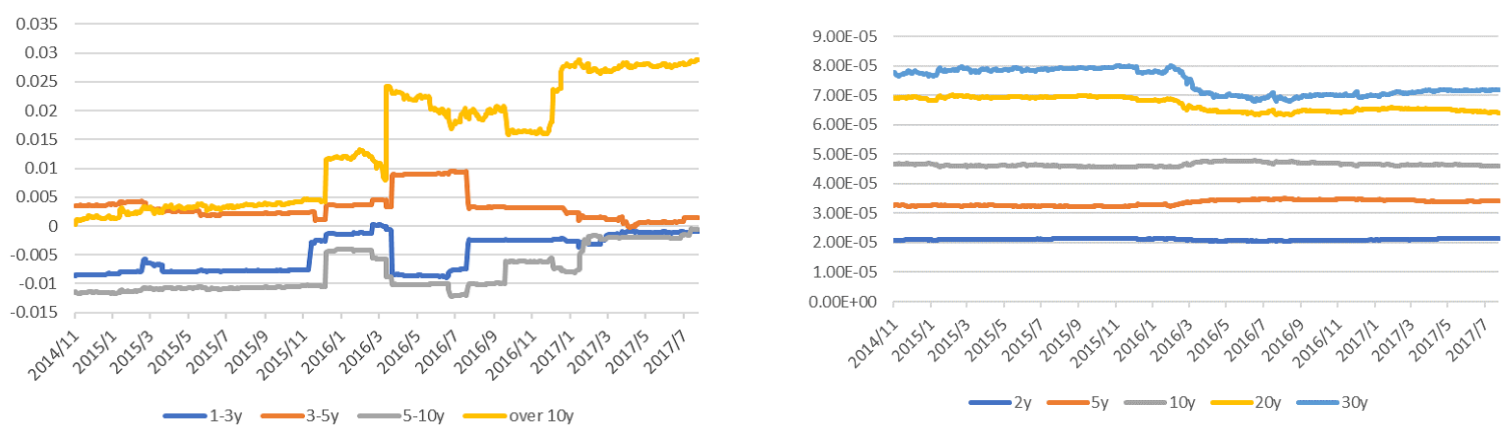

e.sensitivity of $30 \mathrm{y}$ yield against $\operatorname{ENSS},\left(b_{t, 5, j}\right)_{j}$ f.sensitivity of each yield against $\operatorname{MOS},\left(a_{t, i}\right)_{i}$

Besides, it is observed that the sequential estimates of ENSS sometimes show big changes, though they are stable in general. As an example, let us show some interpretation for the large changes in the coefficient of the over 10y ENSS on 30y yield, i.e. $b_{t, 5,4}$ in Fig. 7-e. Namely, it is observed that 4 upward big changes of the coefficient (December 18, 2015/ March 24, 2016/ December 14, 2016/ December 28, 2016), and a downward big change (October 03, 2016), which will be explained below in some details.

(i) The upward big changes of the coefficients in December 18, 2015 can be interpreted as the market response to the first increase in the outright purchase for all sectors at the same time after the introduction of QQE2, which was announced without prior notice.

(ii) The upward big changes of the coefficients in March 24, 2016 can be interpreted as the 
market response to the sudden reduction of the outright purchase for $10-25 \mathrm{y}$ and $25-40 \mathrm{y}$ in the BOJ's operation on the same day.

(iii) The downward big changes of the coefficients in October 03, 2016 can be interpreted as the market response to the news that the outright purchase is unexpectedly almost unchanged in the BOJ's yield curve control (YCC) policy. In fact, the YCC policy was introduced in the monetary policy meeting of Bank of Japan on September 21, 2016, and there was no big change in the first announcement after the introduction of the YCC policy regarding the amount of the outright purchase, which was made after the market close on September 30 .

(iv) The upward big changes of the coefficients in December 14 and 28, 2016 can be interpreted as the market response to the increase and reduction, respectively of the outright purchase for 10-25y and 25-40y at the same time in the BOJ's operation, which is the first time after the introduction of the YCC policy.

From the coefficient results in Fig. 7, the ENSS of the over 10y maturity sector seems to have the largest impact on JGB's yield change among all announcement sectors. However, since the level of the ENSS change is different as shown in Table 8, it is in fact not clear whether the over 10y sector has the biggest effect. Therefore, to analyze the relative impact on the yield change among $E N S S$ sectors, we consider the contribution of the change in $E N S S_{t, j}$ for the change in the $\tau_{i}$-yield, which is defined by

$$
b_{t, i, j} \Delta E N S S_{t, j},
$$

with $\Delta E N S S_{t, j}=E N S S_{t, j}-E N S S_{t-\Delta t, j}$.

Table 8: Average of the absolute change of ENSSs

\begin{tabular}{cccc}
$1-3 y$ & $3-5 y$ & $5-10 y$ & $10 y$ over \\
\hline 0.036 & 0.040 & 0.026 & 0.012
\end{tabular}


Fig. 8: ENSS contribution against yield change

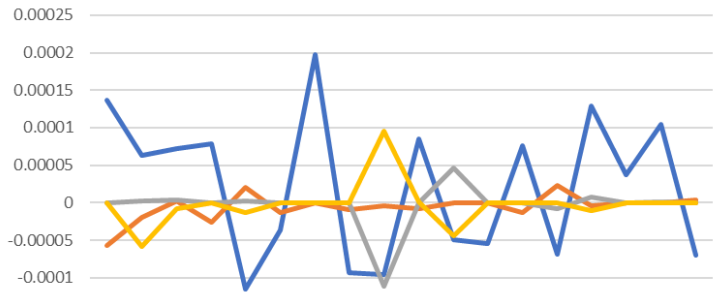

$-0.00015$

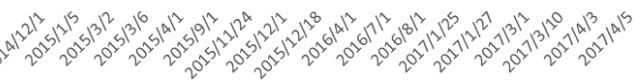

-1-3y ${ }^{3-5 y} \longrightarrow$-10y

ENSS contribution to $2 \mathrm{y}$ yield

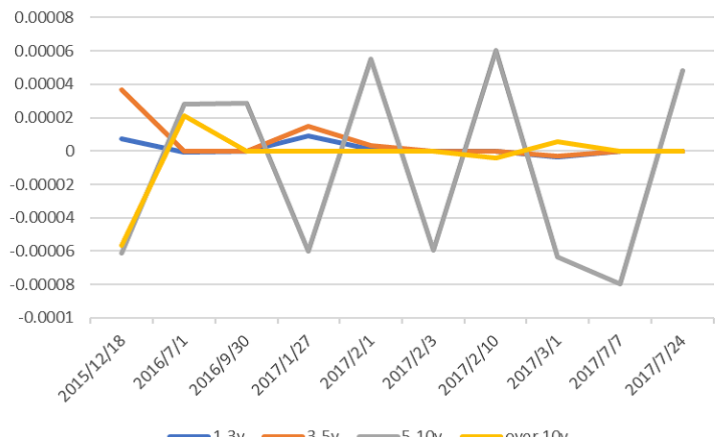

ENSS contribution to $10 \mathrm{y}$ yield

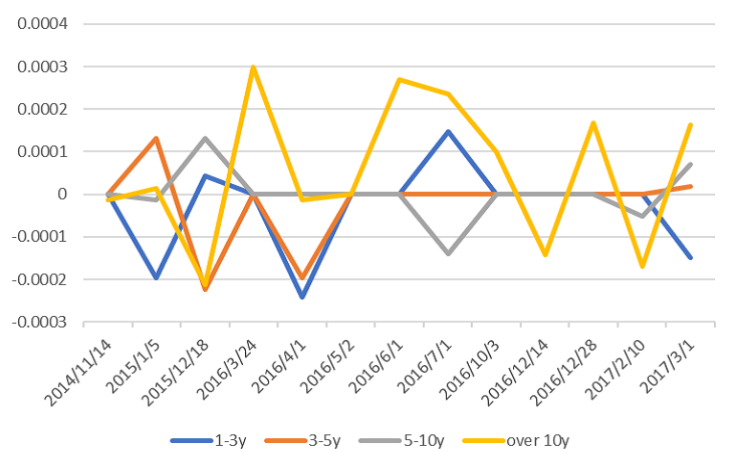

ENSS contribution to 30y yield

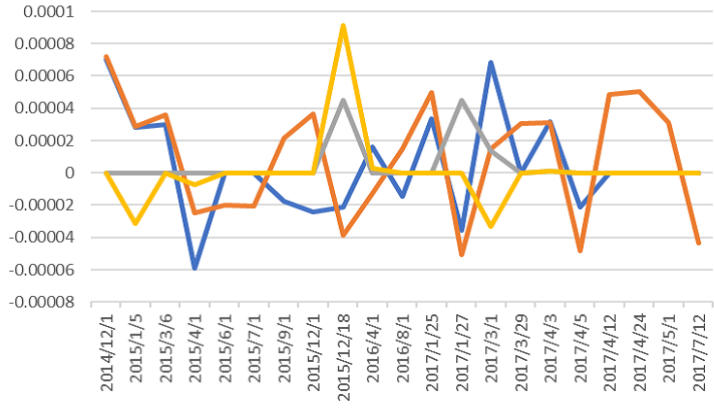

${ }_{1-3 y}{ }^{3-5 y} \longrightarrow$-10y - over $10 y$

ENSS contribution to 5y yield

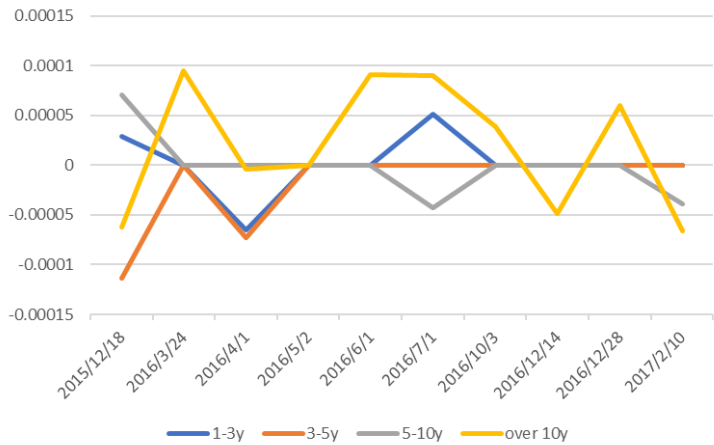

ENSS contribution to $20 \mathrm{y}$ yield

In Fig. 8, we plot the contribution on the day when there is BOJ's announcement on $\tau_{i}$-yield (i.e. 2,5,10,20, or 30 year yield). The figure indicates that the contribution from its own sector's $E N S S$ is the largest except for the 5 year yield. As for the 5 year yield, the 1-3 year sector's ENSS has a large impact, as well as its own (3-5 year) sector's ENSS. 
Fig. 9: Result of yield change tracking

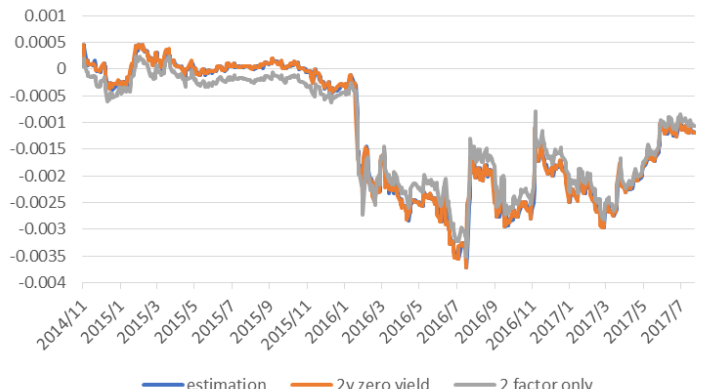

$2 \mathrm{y}$

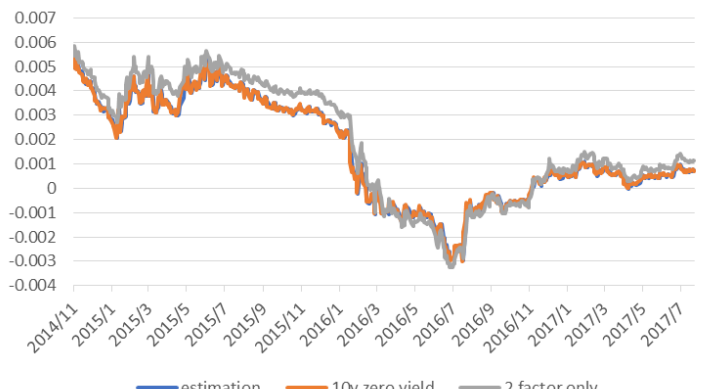

$10 \mathrm{y}$

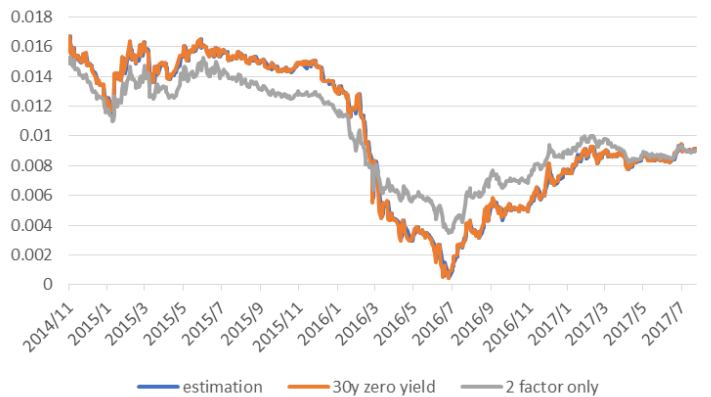

$30 \mathrm{y}$

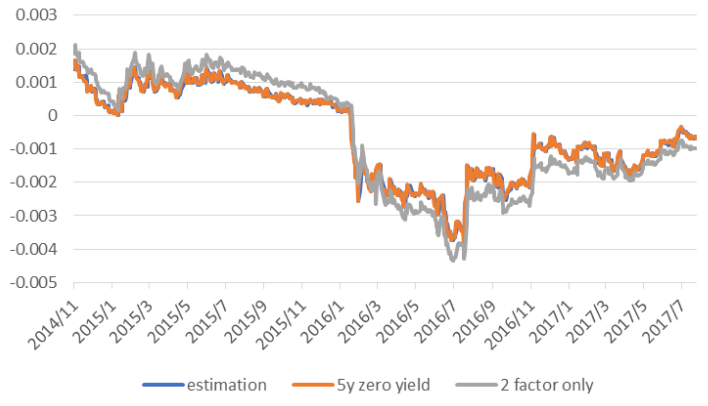

$5 y$

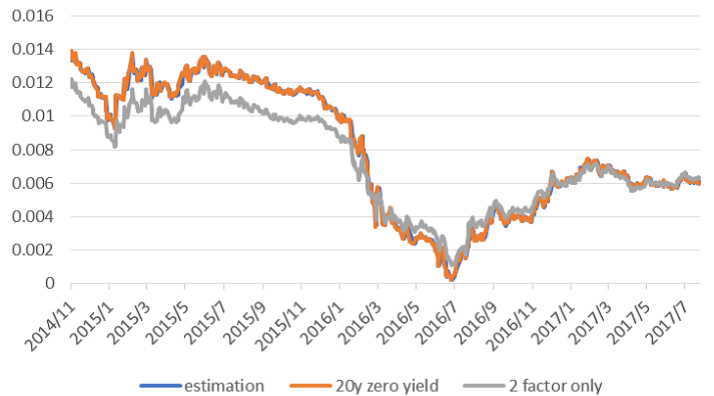

$20 \mathrm{y}$

Fig. 9 shows the time transition of each sector's actual yield and the estimated one based on our model. Here, the yield estimates $\left(\hat{Y}_{t}\left(\tau_{i}\right)\right)_{t, i}$ are calculated by the following equation derived from Eq. (13) in Section 4.1.2:

$$
\hat{Y}_{t}\left(\tau_{i}\right)=\hat{X}_{t, 1}\left(\tau_{i}\right)+\hat{X}_{t, 2}\left(\tau_{i}\right)+\hat{C}\left(\tau_{i}\right)+\hat{a}_{t, i} M O S_{t}+\sum_{j=1}^{4} \hat{b}_{t, i, j} E N S S_{t, j},
$$

where $\hat{X}_{1}, \hat{X}_{2}, \hat{C}\left(\tau_{i}\right), \hat{a}_{t, i}, \hat{b}_{t, i, j}$ denote state variables estimated by Kalman filter. For comparison, we also show the yields "2 factor only" in Fig.9, estimated only by standard level and spread factors $X_{t, 1}\left(\tau_{i}\right), X_{t, 2}\left(\tau_{i}\right)$, that is the zero yields re-calibrated by the terms except $M O S_{t}, E N S S_{t, j}, a_{t, i}, b_{t, i, j}$ in Eq. (13).

Fig. 9 tells us the model's tracking ability of yield dynamics is clearly improved by introducing our new factors. Indeed, our estimates and actual yields are almost indistinguishable in the 
figures. In that sense, our proposed model successfully captures the yield curve changes mainly due to the BOJ's announcements, which can not be explained by the standard level and spread factors.

\subsection{Scenario analysis}

Finally, we implement a scenario analysis based on the estimated results for the over 10 year sector. Namely, under the assumption of maintaining the levels of the overnight and the 10 year rate to be $-0.1 \%$ and $0 \%$, respectively in the current YCC framework, we set the following two exit scenarios: (I) reduction of the BOJ's outright purchase to the amount in October 2014 (the end of QQE1) only for the over 10 year sector of JGB. (II) termination of the outright purchase only for the over 10 year sector.

Because the coefficients of ENSS of the over $10 \mathrm{y}$ sector on the $20 \mathrm{y}$ and $30 \mathrm{y}$ yields, $b_{t, 4,4}$ (over 10y in Fig.7-d.) and $b_{t, 5,4}$ (over 10y in Fig.7-e.) have been stable since 2016/12/28, we use the averages of the estimated values since then for the scenario analysis, that is 0.010352 and 0.027733. The result tells us that in Scenario (I) the 20 year and 30 year yields will increase by $5.4 \mathrm{bps}$ and $14.6 \mathrm{bps}$, respectively, while $9.8 \mathrm{bps}$ and $26.2 \mathrm{bps}$ in Scenario (II). We also note that the spread between 20 and 30 year yields becomes widen by 9.1 bps in Scenario (I) and 16.4 bps in Scenario (II).

However, our analysis in the previous subsection indicates that changes in the BOJ policy for the outright purchase largely affect the ENSS coefficients. Especially, the coefficients of ENSS for its own sector are expected to show a big upward increase accompanied by the realization of each scenario. Hence, we incorporate the increase into the analyses in a simple way that the coefficients of $E N S S, b_{t, 4,4}$ and $b_{t, 5,4}$, are assumed to increase by the same amount (i.e. +0.0027 and +0.0072 , respectively) as on December 18, 2015, when one observes the first jump after QQE2 in Fig. 7-d and e.

In addition, we normally observe changes in the level and spread factors (i.e. $x_{1} \& x_{2}$ ) simultaneously with ENSS changes. In particular, drastic reduction in ENSS for the over 10 year sector is expected to affect the level and spread factors, which also causes the yield changes.

To see the effect, we implement a simple regression analysis, where an independent variable is ENSS over the 10 year sector (i.e. $E N S S_{t, 4}$ ), and a dependent variable is $\hat{x}_{t, 1}$ or $\hat{x}_{t, 2}$ estimated by Kalman filter in Section 4.2. That is, the regression equation is given as $\hat{x}_{t, i}=$ $c_{i} \times E N S S_{t, 4}+d_{i}(i=1,2)$ with regression coefficient $c_{i}$ and intercept $d_{i}$. The result is shown in Table 9.

Table 9: Result of regression analysis

\begin{tabular}{ccc|ccc}
$x_{1}$ & Estimate & $t$ value & $x_{2}$ & Estimate & $t$ value \\
\hline Coefficient $\left(c_{1}\right)$ & 0.050 & 8.215 & Coefficient $\left(c_{2}\right)$ & -0.068 & -10.290 \\
Intercept $\left(d_{1}\right)$ & -0.032 & -90.001 & Intercept $\left(d_{2}\right)$ & 0.027 & 70.808
\end{tabular}

Then, in addition to the direct impact of the ENSS reduction, the observation equation in Eq. (13) with the regression coefficients provides the indirect effect on the yields through changes in level and spread factors.

The results are given in Table 10 and 11 below, where the indirect effect through changes in level and spread factors expand the features observed in the above result without considering the jumps of ENSS's coefficients and the indirect effect. Namely, it shows much more increase in the yield levels and widening in the 20-30 year spread: In Scenario (I), the 20 and 30 year yields will increase by $27.4 \mathrm{bps}$ and $40.8 \mathrm{bps}$, respectively with $13.4 \mathrm{bps}$ widening of their spread. 
In Scenario (II), they will increase by $49.2 \mathrm{bps}$ and $73.4 \mathrm{bps}$, respectively with $24.2 \mathrm{bps}$ widening of their spread.

Our future research will develop a more consistent method which integrates the current analysis with the one in Section 4.1-4.2 as well as with an endogeneity problem mentioned in Section 4.1.2.

Table 10: Scenario (I)

\begin{tabular}{c|c|c|c|c|c|c} 
& $\begin{array}{c}\text { Current BOJ’s } \\
\text { outright purchase } \\
\text { (¥ trillion/year) }\end{array}$ & $\begin{array}{c}\text { Outright purchase } \\
\text { after policy change } \\
\text { (¥ trillion/year) }\end{array}$ & $\begin{array}{c}\text { Yield change } \\
\text { from ENSS } \\
\text { factor }(\text { bps })\end{array}$ & $\begin{array}{c}\text { Yield change } \\
\text { from level } \\
\text { factor }(\text { bps })\end{array}$ & $\begin{array}{c}\text { Yield change } \\
\text { from spread } \\
\text { factor }(\text { bps })\end{array}$ & $\begin{array}{c}\text { Yield change } \\
\text { from all } \\
\text { factors }(\text { bps })\end{array}$ \\
\hline $10 \mathrm{y}$ & 29.52 & 29.52 & 0.6 & 26.4 & -11.3 & 15.7 \\
$20 \mathrm{y}$ & 12 & 6.12 & 6.9 & 26.4 & -5.9 & 27.4 \\
$30 \mathrm{y}$ & 6 & 1.86 & 18.4 & 26.4 & -4.0 & 40.8
\end{tabular}

Table 11: Scenario (II)

\begin{tabular}{c|c|c|c|c|c|c} 
& $\begin{array}{c}\text { Current BOJ's } \\
\text { outright purchase } \\
\text { (¥ trillion/year) }\end{array}$ & $\begin{array}{c}\text { Outright purchase } \\
\text { after policy change } \\
\text { (¥ trillion/year) }\end{array}$ & $\begin{array}{c}\text { Yield change } \\
\text { from ENSS } \\
\text { factor }(b p s)\end{array}$ & $\begin{array}{c}\text { Yield change } \\
\text { from level } \\
\text { factor }(b p s)\end{array}$ & $\begin{array}{c}\text { Yield change } \\
\text { from spread } \\
\text { factor }(b p s)\end{array}$ & $\begin{array}{c}\text { Yield change } \\
\text { from all } \\
\text { factors }(b p s)\end{array}$ \\
\hline $10 \mathrm{y}$ & 29.52 & 29.52 & 1.0 & 47.5 & -20.3 & 28.1 \\
$20 \mathrm{y}$ & 12 & 0 & 12.4 & 47.5 & -10.7 & 49.2 \\
$30 \mathrm{y}$ & 6 & 0 & 33.0 & 47.5 & -7.1 & 73.4
\end{tabular}

\section{Conclusion}

This study has examined the impact of the BOJ's outright JGB purchase on the term structure of interest rates during 2014/10/22-2017/8/3, that is from the end of QQE1 to the current QQE2 period. Particularly, we have developed a simple model with filtering technique, which takes expectation for the future net supply in the JGB secondary market and the current market outstanding into account. Moreover, our empirical investigation has estimated the sensitivities of interest rates against the changes in the market expectation for the net supply with each sector of JGB. We expect that the analysis can be used to quantify the effect on the term structure by a policy change such as an announcement on termination or significant reduction of the BOJ's outright purchase.

Further we have implemented a scenario analysis based on the estimated result to obtain the quantitative impacts of the BOJ's exit strategy on the interest rates. The result shows substantial increase in the 30 year yield with widening of 20-30 year spread. We also remark that a similar analysis is applied to an estimate of the effect on the yield curve by changes in the Ministry of Finace (MOF)'s issuance plan of JGB. (See Section 5 in Nakano, Takahashi, Takahashi and Tokioka (2017) for the detail.)

Our next research topics will include an extension of the current work to estimate the impact of QQE1(April 2013-October 2014) on the JGB yield curve.

\section{Acknowledgement}

The authors would like to express the deep appreciation to Professor Kazuo Ueda and Professor Kiyohiko Nishimura for their valuable suggestions. We are also grateful to Mr. Takahiko Suenaga for his comments. We thank Mr. Keita Suzuki for his support in the data construction. This 
research is supported by CARF (Center for Advanced Research in Finance). Also, this work is supported by JSPS KAKENHI Grant Numbers JP17J09046 and JP17J09127.

\section{Appendix: Derivation of Equation (12)}

Recall that $x_{t, 1}$ and $x_{t, 2}$ follows stochastic processes (10) and (11), respectively. Then,

$$
\begin{gathered}
\int_{t}^{T} x_{s, 1} d s=x_{t, 1} \tau+\frac{\lambda}{2} \tau^{2}+\sigma_{1} \int_{0}^{\tau}(\tau-u) d W_{u, 1}^{\mathbb{Q}}, \\
\int_{t}^{T} x_{s, 2} d s=\frac{1-e^{-\kappa \tau}}{\kappa} x_{t, 2}+\frac{\sigma_{2}}{\kappa} \int_{0}^{\tau}\left(1-e^{\kappa(u-\tau)}\right) d W_{u, 2}^{\mathbb{Q}} .
\end{gathered}
$$

The above two equations derive the following equation with the assumption that the short rate $r_{t}$ is the sum of two variables, i.e. Eq. (9):

$$
\begin{aligned}
& P(t, T)=\mathbb{E}^{\mathbb{Q}}\left[e^{-\int_{t}^{T} r_{s} d s} \mid \mathcal{F}_{t}\right]=\mathbb{E}^{\mathbb{Q}}\left[e^{-\int_{t}^{T}\left(x_{s, 1}+x_{s, 2}\right) d s} \mid \mathcal{F}_{t}\right] \\
& =\exp \left\{-x_{t, 1} \tau-\frac{\lambda}{2} \tau^{2}-\frac{1-e^{-\kappa \tau}}{\kappa} x_{t, 2}\right\} \times \\
& \mathbb{E}^{\mathbb{Q}}\left[\exp \left\{-\sigma_{1} \int_{0}^{\tau}(\tau-u) d W_{u, 1}^{\mathbb{Q}}-\frac{\sigma_{2}}{\kappa} \int_{0}^{\tau}\left(1-e^{\kappa(u-\tau)}\right) d W_{u, 2}^{\mathbb{Q}}\right\}\right]
\end{aligned}
$$

Remark that

$$
\int_{0}^{\tau}(\tau-u) d W_{u, 1}^{\mathbb{Q}}=\int_{0}^{\tau}(\tau-u) \sqrt{1-\rho^{2}} d \tilde{W}_{u, 1}^{\mathbb{Q}}+\int_{0}^{\tau}(\tau-u) \rho d W_{u, 2}^{\mathbb{Q}}
$$

where $\tilde{W}_{t, 1}^{\mathbb{Q}}$ is a one dimensional Brownian motion independent of $W_{t, 2}^{\mathbb{Q}}$, i.e. $\tilde{W}_{t, 1}^{\mathbb{Q}} \Perp W_{t, 2}^{\mathbb{Q}}$, under a risk-neutral measure $\mathbb{Q}$. Then,

$$
\begin{aligned}
& \mathbb{E}^{\mathbb{Q}}\left[\exp \left\{-\sigma_{1} \int_{0}^{\tau}(\tau-u) d W_{u, 1}^{\mathbb{Q}}-\frac{\sigma_{2}}{\kappa} \int_{0}^{\tau}\left(1-e^{\kappa(u-\tau)}\right) d W_{u, 2}^{\mathbb{Q}}\right\}\right] \\
& =\mathbb{E}^{\mathbb{Q}}\left[\exp \left\{-\sigma_{1} \int_{0}^{\tau}(\tau-u) \sqrt{1-\rho^{2}} d \tilde{W}_{u, 1}^{\mathbb{Q}}\right\}\right] \times \\
& \mathbb{E}^{\mathbb{Q}}\left[\exp \left\{-\sigma_{1} \int_{0}^{\tau}(\tau-u) \rho d W_{u, 2}^{\mathbb{Q}}-\frac{\sigma_{2}}{\kappa} \int_{0}^{\tau}\left(1-e^{\kappa(u-\tau)}\right) d W_{u, 2}^{\mathbb{Q}}\right\}\right]
\end{aligned}
$$

Since $\operatorname{Var}\left[\sigma_{1} \int_{0}^{\tau}(\tau-u) \sqrt{1-\rho^{2}} d \tilde{W}_{u, 1}^{\mathbb{Q}}\right]=\sigma_{1}^{2}\left(1-\rho^{2}\right) \tau^{3} / 3$,

$$
\begin{aligned}
& \mathbb{E}^{\mathbb{Q}}\left[\exp \left\{-\sigma_{1} \int_{0}^{\tau}(\tau-u) \sqrt{1-\rho^{2}} d \tilde{W}_{u, 1}^{\mathbb{Q}}\right\}\right]=\exp \left\{\frac{\sigma_{1}^{2}\left(1-\rho^{2}\right)}{6} \tau^{3}\right\} \\
& \mathbb{E}^{\mathbb{Q}}\left[\exp \left\{-\sigma_{1} \int_{0}^{\tau}(\tau-u) \rho d W_{u, 2}^{\mathbb{Q}}-\frac{\sigma_{2}}{\kappa} \int_{0}^{\tau}\left(1-e^{\kappa(u-\tau)}\right) d W_{u, 2}^{\mathbb{Q}}\right\}\right] \\
& =\mathbb{E}^{\mathbb{Q}}\left[\exp \left\{-\int_{0}^{\tau}\left\{\rho \sigma_{1}(\tau-u)+\frac{\sigma_{2}}{\kappa}\left(1-e^{\kappa(u-\tau)}\right)\right\} d W_{u, 2}^{\mathbb{Q}}\right\}\right] \\
& =\mathbb{E}^{\mathbb{Q}}\left[\exp \left\{-\int_{-\tau}^{0}\left\{-\rho \sigma_{1} z+\frac{\sigma_{2}}{\kappa}\left(1-e^{\kappa z}\right)\right\} d W_{z, 2}^{\mathbb{Q}}\right\}\right] ; z:=u-\tau
\end{aligned}
$$


Since

$$
\begin{aligned}
& \operatorname{Var}\left[\int_{-\tau}^{0}\left\{-\rho \sigma_{1} z+\frac{\sigma_{2}}{\kappa}\left(1-e^{\kappa z}\right)\right\} d W_{z, 2}^{\mathbb{Q}}\right] \\
& =\int_{-\tau}^{0}\left\{\rho^{2} \sigma_{1}^{2} z^{2}+\left(\frac{\sigma_{2}}{\kappa}\right)^{2}\left(1-e^{\kappa z}\right)^{2}-2 \frac{\rho \sigma_{1} \sigma_{2}}{\kappa} z\left(1-e^{\kappa z}\right)\right\} d z \\
& =\frac{\rho^{2} \sigma_{1}^{2}}{3} \tau^{3}-2 A(\tau)-2 \frac{\rho \sigma_{1} \sigma_{2}}{\kappa} \int_{-\tau}^{0}\left(z-z e^{\kappa z}\right) d z=\frac{\rho^{2} \sigma_{1}^{2}}{3} \tau^{3}-2 A(\tau)+2 \frac{\rho \sigma_{1} \sigma_{2}}{\kappa}\left\{\frac{\tau^{2}}{2}+\frac{\tau e^{-\kappa \tau}-B(\tau)}{\kappa}\right\},
\end{aligned}
$$

$$
\begin{aligned}
& \mathbb{E}^{\mathbb{Q}}\left[\exp \left\{-\int_{-\tau}^{0}\left\{-\rho \sigma_{1} z+\frac{\sigma_{2}}{\kappa}\left(1-e^{\kappa z}\right) d W_{z, 2}^{\mathbb{Q}}\right\}\right\}\right] \\
& =\exp \left[\frac{\rho^{2} \sigma_{1}^{2}}{6} \tau^{3}-A(\tau)+\frac{\rho \sigma_{1} \sigma_{2}}{\kappa}\left\{\frac{\tau^{2}}{2}+\frac{\tau e^{-\kappa \tau}-B(\tau)}{\kappa}\right\}\right]
\end{aligned}
$$

Eq. (18), (20), (21) and (24) derive Eq. (12).

\section{References}

[1] Babbs, S. H., \& Nowman, K. B. (1999). Kalman filtering of generalized Vasicek term structure models. Journal of Financial and Quantitative Analysis, 34(1), 115-130.

[2] Christiano, L. J., Eichenbaum, M., \& Evans, C. L. (1999). Monetary policy shocks: What have we learned and to what end?. Handbook of macroeconomics, 1, 65-148.

[3] Diaz, D., Theodoulidis, B., \& Dupouy, C. (2016). Modelling and forecasting interest rates during stages of the economic cycle: A knowledge-discovery approach. Expert Systems with Applications, 44, 245-264.

[4] Fujii, M., Shimada, Y., \& Takahashi, A. (2010). A note on construction of multiple swap curves with and without collateral. FSA research review, 6, 139-157.

[5] Fujii, M., \& Takahashi, A. (2011). Choice of collateral currency. Risk Magazine, January 2011, pp.120-125, 2011

[6] Fukui, T., Sato, S., Takahashi, A. (2017). Style analysis with particle filtering and generalized simulated annealing. International Journal of Financial Engineering Vol. 04, No. 02n03, 1750037

[7] Fukunaga Ichiro, Naoya Kato, and Junko Koeda (2015). Maturity Structure and Supply Factors in Japanese Government Bond Markets. Monetary and Economic Studies, 33, pp. 45-95.

[8] Geyer, A. L., \& Pichler, S. (1999). A STATE-SPACE APPROACH TO ESTIMATE AND TEST MULTIFACTOR COX-INGERSOLL-ROSS MODELS OF THE TERM STRUCTURE. Journal of Financial Research, 22(1), 107-130.

[9] Gordon, D. B., \& Leeper, E. M. (1994). The dynamic impacts of monetary policy: an exercise in tentative identification. Journal of Political Economy, 102(6), 1228-1247. 
[10] Hamilton, J. D., \& Wu, J. C. (2012). The effectiveness of alternative monetary policy tools in a zero lower bound environment. Journal of Money, Credit and Banking, 44(s1), 3-46.

[11] Heath, D., Jarrow, R., \& Morton, A. (1992). Bond pricing and the term structure of interest rates: A new methodology for contingent claims valuation. Econometrica: Journal of the Econometric Society, 77-105.

[12] Heidari, M., \& Wu, L. (2003). Are interest rate derivatives spanned by the term structure of interest rates?. The Journal of Fixed Income, 13(1), 75-86.

[13] Ho, T. S., \& LEE, S. B. (1986). Term structure movements and pricing interest rate contingent claims. the Journal of Finance, 41(5), 1011-1029.

[14] Hull, J., \& White, A. (1990). Pricing interest-rate-derivative securities. The Review of Financial Studies, 3(4), 573-592.

[15] Jarrow, R., \& Li, H. (2014). The impact of quantitative easing on the US term structure of interest rates. Review of Derivatives Research, 17(3), 287-321.

[16] Kalman, R. E. (1960). A new approach to linear filtering and prediction problems. Journal of basic Engineering, 82(1), 35-45.

[17] Kalman, R. E., \& Bucy, R. S. (1961). New results in linear filtering and prediction theory. Journal of basic engineering, 83(1), 95-108.

[18] Nakano, M., Takahashi, A., \& Takahashi, S. (2017). Generalized exponential moving average (EMA) model with particle filtering and anomaly detection. Expert Systems with Applications, 73, 187-200.

[19] Nakano, M., Takahashi, A., \& Takahashi, S. (2017). Creating investment scheme with state space modeling. Expert Systems with Applications, 81, 53-66.

[20] Nakano, M., Takahashi, A., \& Takahashi, S. (2017). Fuzzy logic-based portfolio selection with particle filtering and anomaly detection. Knowledge-Based Systems.

[21] Nakano, M., Takahashi, A., Tokioka, T., \& Takahashi, S. (2017). Effect on the yield curve by the net supply changes of JGB. Preprint.(in Japanese)

[22] Oda, N., \& Ueda, K. (2007). The Effects of the Bank of Japan's Zero Interest Rate Commitment and Quantitative Monetary Easing on the Yield Curve: A Macro- Finance Approach. The Japanese Economic Review, 58(3), 303-328.

[23] Oh, K. J., \& Han, I. (2000). Using change-point detection to support artificial neural networks for interest rates forecasting. Expert systems with applications, 19(2), 105-115.

[24] Shreve, S. E. (2004). Stochastic calculus for finance II: Continuous-time models (Vol. 11). Springer Science \& Business Media.

[25] Streit, R. E., \& Borenstein, D. (2012). Design and development of a fuzzy agent-based model to measure interest rate expectations. Expert Systems with Applications, 39(8), 7391-7402.

[26] Strongin, S. (1995). The identification of monetary policy disturbances explaining the liquidity puzzle. Journal of Monetary Economics, 35(3), 463-497. 
[27] Takahashi, A., \& Sato, S. (2001). A Monte Carlo filtering approach for estimating the term structure of interest rates. Annals of the Institute of Statistical Mathematics, 53(1), 50-62.

[28] Takahashi, A., \& Sato, S. (2002). An Application of Monte Carlo filter for estimating the term structure of interest rates. Proceedings of the Institute of Statistical Mathematics, 50(2), 133-147.(in Japanese)

[29] Tsuda, H. (2003). Prediction of individual bond prices via a dynamic bond pricing model: Application to japanese government bond price data. Asia-Pacific Financial Markets, 10(1), $59-85$.

[30] Vasicek, O. (1977). An equilibrium characterization of the term structure. Journal of financial economics, 5(2), 177-188. 